\title{
PRODUÇÃO DE MATERIAL DIDÁTICO DE LEITURA EM LÍNGUA INGLESA ATRAVÉS DE PROVÉRBIOS
}

\section{PRODUCTION OF ENGLISH LANGUAGE READING DIDACTIC MATERIAL THROUGH PROVERBS}

\author{
Bianka Barbosa Ferreira ${ }^{1}$; Daniel de Sá Rodrigues ${ }^{2}$
}

\section{RESUMO}

O presente trabalho tem como objetivo descrever a organização do material didático de leitura em inglês por meio dos provérbios. A pesquisa está fundamentada teoricamente nas noções de leitura, de material didático e de provérbio como unidade fraseológica, como gênero textual e como objeto de ensino de língua. A metodologia é descritiva, de natureza qualitativa. No primeiro momento, foram analisados quatro livros didáticos de inglês do primeiro ano do Ensino Médio para identificar os conteúdos gramaticais e as respectivas sequências estabelecidos nestes livros, que serviram de base para a elaboração de uma sequência gramatical que funcionou como parâmetro para a seleção e ordenação sequencial de dez provérbios que compõem o material. Quanto à elaboração do material, cada provérbio é explorado em uma unidade didática através de explicações e questões que envolvem conhecimento prévio do provérbio, vocabulário, gramática, verificação de conhecimento adquirido sobre o provérbio ao final da unidade didática e reflexão sobre a aprendizagem. O material produzido foi aplicado com discentes do segundo ano do Ensino Médio Integrado ao Ensino Técnico em Edificações do Instituto Federal da Paraíba (IFPB) Campus Catolé do Rocha. Por fim, o material foi avaliado pelos alunos e posteriormente revisado. Os estudantes relataram que o material é produtivo, ajudando-os a aprender várias palavras e expressões em inglês e a refletir sobre o significado dos provérbios, aprendendo lições de vida expressas por estas frases. Como um gênero textual de extensão curta, os provérbios demonstram que são bastante eficazes para o aprendizado tanto de língua quanto de lições de vida.

Palavras-Chave: Pesquisa, Graduação, Discente, Educação Básica.

\begin{abstract}
The present work aims to describe the organization of English language reading didactic material through proverbs. The research is theoretically based on the notions of reading, didactic material and proverb as a phraseological unit, as a textual genre and an object of language teaching. The methodology is descriptive and qualitative. At the first moment, four English textbooks of first year of High School were analyzed to identify the grammatical contents and the respective sequences established in these books, which served as the basis for the elaboration of a grammatical sequence that functioned as a parameter for selection and sequential ordering of ten proverbs that make up the material. As for the preparation of the material, each proverb is explored in a didactic unit through explanations and questions that involve prior knowledge of the proverb, vocabulary, grammar, verification of knowledge acquired on the proverb at the end of the didactic unit and reflection on learning. The material produced was applied with students from the second year of High School Integrated to the Technical Education in Building at Federal Institute of Paraíba (IFPB) Campus Catolé do Rocha. Finally, the material was evaluated by the students and later revised. The students reported that the material is productive, helping them to learn many words and expressions in

\footnotetext{
${ }^{1}$ Curso Técnico Integrado em Edificações, Instituto Federal da Paraíba - Campus Catolé do Rocha, e-mail: biankabbf@gmail.com

${ }^{2}$ Mestre em Linguística Aplicada pela Universidade Estadual do Ceará (UECE), professor de Língua Inglesa no Instituto Federal da Paraíba - Campus Catolé do Rocha, e-mail: danielmartyniano@bol.com.br
} 
English and reflecting on the meaning of proverbs, learning life lessons expressed by these sentences. As a textual genre of short duration, proverbs demonstrate that they are quite effective in learning both language and life lessons.

Keywords: Didactic Material, Proverbs, Reading.

\section{INTRODUÇÃO}

A leitura em língua inglesa é uma habilidade amplamente requerida tanto no contexto acadêmico quanto no profissional. Considerando que a aquisição da habilidade de leitura em língua estrangeira requer muita dedicação por parte do aluno, os materiais didáticos elaborados para o ensino de leitura devem incentivar o aprendiz a desenvolver esta habilidade. Uma das formas de promover esta motivação é a aprendizagem de leitura em inglês através de provérbios.

Por serem curtos e de uso amplo, os provérbios podem ser úteis no processo de ensinoaprendizagem de inglês, especialmente para alunos do Ensino Médio, que necessitam desenvolver a habilidade de leitura. A experiência docente mostra que, muitas vezes, esses estudantes não aprenderam inglês o esperado no Ensino Fundamental e sentem muita dificuldade ao iniciar seus estudos do idioma no Ensino Médio, pois os livros didáticos neste nível de ensino, desde o primeiro ano, já trabalham com textos maiores, pressupondo que os alunos já tenham base suficiente para a leitura destes textos. É necessário, então, adaptar o ensino de leitura de língua inglesa para que o concluinte do Ensino Fundamental possa mais rapidamente chegar ao nível adequado de leitura que se espera de um discente de Ensino Médio. O uso dos provérbios, portanto, pode ser eficaz nesta adaptação.

Uma vez que se decide elaborar um material didático de leitura em inglês por meio de provérbios, é necessário levantar a seguinte questão: de que forma este material pode ser estruturado, visando a eficiência no aprendizado de leitura em inglês? Desse modo, o presente trabalho, fruto de um projeto de pesquisa submetido para o Programa Institucional de Bolsas de Iniciação Científica para o Ensino Médio - PIBIC-EM/CNPq, realizado no Instituto Federal da Paraíba - IFPB - tem como objetivo descrever a organização de um material didático de leitura em língua inglesa através de provérbios.

$\mathrm{Na}$ fundamentação teórica do trabalho estão as noções de leitura, de material didático e de provérbio como unidade fraseológica, como gênero textual e como objeto de ensino de língua. Esta pesquisa, cuja metodologia é descritiva, de natureza qualitativa, tem potencial de contribuir para os estudos de Linguística Aplicada, haja vista que o provérbio, como objeto de estudo, tanto do ponto de vista dos gêneros textuais quanto do ponto de vista do ensinoaprendizagem de línguas, ainda tem muito a ser explorado. 


\section{FUNDAMENTAÇÃO TEÓRICA}

De acordo com Dell'isola (2001), a leitura é um ato de interação e construção de significado para o texto. Ao ter contato com o texto, o leitor ativa diversos conhecimentos: “conhecimentos e crenças sobre o mundo, conhecimentos de diferentes tipos de textos, de sua organização e estrutura, conhecimentos lexicais, sintáticos, semânticos, discursivos e pragmáticos" (DELL'ISOLA, 2011, p. 37). Almeida (2013) segue a mesma linha de conceituação de leitura como processo de interação entre autor, leitor e texto, acrescentando a importância no contexto de ensino-aprendizagem.

É fundamental que o aluno reconheça os vários tipos de gêneros textuais para melhor compreensão e interação com os textos em língua estrangeira, saindo assim dos limites linguísticos, com a simples tradução dos termos, por exemplo. Dentre os gêneros textuais estão os provérbios. O provérbio é considerado como uma unidade léxica fraseológica, fixa, materializada e convalidada por determinada comunidade linguística, que reúne experiências vivenciadas em comum e as formula como um enunciado conotativo, breve e completo, com a finalidade de aconselhar, ensinar, persuadir, enfatizar, advertir, consolar, repreender, incentivar e outros objetivos fixados pelo contexto em que são utilizados (AZEVEDO e FERNANDES, 2009; LIMA, 2011; XATARA e SUCCI, 2008). O provérbio, como gênero textual, adequa-se na tipologia do senso comum devido a sua projeção em formações discursivas de vasta veiculação entre vários grupos sociais (AZEVEDO e FERNANDES, 2009).

Lima (2011) afirma que o "trabalho com provérbios ajuda o aluno a pensar na língua alvo, ao invés de procurar fazer tradução literal” (p. 240). Recorrendo a Schmidt e Lacaz-Ruiz, Lima mostra que o trabalho com os provérbios dá a oportunidade para o resgate de valores através de temas como "autoconfiança, determinação, força de vontade, qualidade de vida, cidadania e solidariedade, entre muitos outros" (p. 240). Assim, uma vantagem de aprender uma língua estrangeira através de provérbios é que o estudante, ao mesmo tempo, aprende aspectos linguísticos (como vocabulário e gramática) e valores pessoais, ou seja, uma lição de vida.

O trabalho com provérbios no ambiente escolar pode ser explorado com materiais didáticos. Salas (2004, apud VILAÇA, 2009) define materiais didáticos como tudo que os professores e alunos utilizam para facilitar a aprendizagem. A lista de materiais didáticos é extensa, podendo ser livros didáticos, resumos, tarefas, $\mathrm{CDs}$, dicionários, exercícios fotocopiados, entre outros. Os materiais didáticos desempenham papel importante no contexto de ensino-aprendizagem de línguas estrangeiras, pois apresentam a explicação do conteúdo e exercícios de fixação, que podem ser utilizados em qualquer local e momento. 
Quando à produção de materiais didáticos, vários autores tem se dedicado a esta área, entre os quais, Leffa (2007), para quem a produção de um material deve passar por quatro momentos: análise (observação das necessidades de aprendizagem dos estudantes), desenvolvimento (definição, dentre outras coisas, do conteúdo), implementação (utilização do material pelo aluno) e avaliação (verificação da necessidade de melhoria no material). A produção do material didático descrito nesta pesquisa seguiu o processo recomendado por Leffa.

\section{METODOLOGIA}

A pesquisa relatada neste trabalho é descritiva, de natureza qualitativa, em que se discorre sobre o processo de elaboração do material didático de leitura em língua inglesa através dos provérbios.

No primeiro momento, foram analisados quatro livros didáticos de língua inglesa do primeiro ano do Ensino Médio (DIAS; JUCÁ; FARIA, 2013; MENEZES et al., 2013; TAVARES; FRANCO, 2013; TILIO, 2016) para identificar os conteúdos gramaticais e as respectivas sequências estabelecidos nestes livros. Com base na comparação destas sequências, foi elaborada uma sequência gramatical básica que serviu de parâmetro para a seleção e ordenação sequencial de dez provérbios extraídos de um site na internet (PHRASEMIX, 2018) e de um dicionário de provérbios (SPEAKE, 2008).

Com os provérbios selecionados e organizados, partiu-se para a elaboração do material didático de leitura em língua inglesa com base nesses provérbios. Para cada provérbio foram elaborados atividades de tradução do vocabulário, explicações dos tópicos gramaticais envolvidos no provérbio com exercícios, e atividades relacionadas ao significado do provérbio.

Com o material finalizado, foi realizada a aplicação e observação da eficácia desse material com discentes do $2^{\circ}$ ano do Curso Técnico Integrado ao Ensino Médio em Edificações, no Instituto Federal da Paraíba, Campus Catolé do Rocha. Na matriz curricular do curso, as disciplinas de Língua Inglesa são ministradas no $2^{\circ}$ e $3^{\circ}$ anos do Ensino Médio integrado ao Ensino Técnico, consequentemente, as turmas do $2^{\circ}$ ano são as que vão ter contato inicial formal com o idioma no Ensino Médio, justificando a aplicação do material didático com os provérbios com os alunos destas turmas, visando à preparação para leitura de textos de extensão maior. No final da aplicação do material, os estudantes envolvidos foram consultados sobre a eficácia do material. A última fase da pesquisa foi a revisão do material, corrigindo algumas inconsistências encontradas durante a sua aplicação com os discentes. 


\section{RESULTADOS E DISCUSSÃO}

Através de sucessivas aulas de língua inglesa, percebeu-se que uma grande parte dos estudantes do IFPB Campus Catolé do Rocha apresentava a necessidade de desenvolver a habilidade de leitura. Com esta análise, nos termos de Leffa (2007), decidiu-se por estabelecer um parâmetro básico de sequências gramaticais que fundamentaria a construção do material didático de leitura em língua inglesa através de provérbios. Esta decisão baseia-se no fato de que o ensino de língua inglesa geralmente segue uma ordem, muitas vezes influenciada pela gramática. Determinados tópicos gramaticais só podem ser mais bem compreendidos se tiver uma noção de tópicos que lhe servem de base.

Ademais, a gramática, junto com o vocabulário, é fundamental para compreensão de textos, independente da extensão, se é uma frase, como os provérbios, ou um livro inteiro de várias páginas. Assim, dando início a fase de desenvolvimento, proposto por Leffa (2007), especificamente na seleção de conteúdos, foram coletados quatro livros didáticos de língua inglesa do primeiro ano do Ensino Médio para verificar quais tópicos gramaticais são abordados e qual a ordem destes tópicos. Com base nesta análise, foi elaborada uma sequência gramatical básica.

Em seguida, os provérbios foram coletados das fontes citadas na metodologia. A princípio, pretendia-se que todos os tópicos gramaticais fossem contemplados com os provérbios, porém, o material a ser elaborado ficaria muito extenso, considerando o públicoalvo do material didático, aprendizes iniciantes de leitura em língua inglesa.

O número de provérbios coletados inicialmente era cerca de vinte e cinco, porém, com a proposta de reduzir o material, justificada acima, optou-se por selecionar dez provérbios. A seleção levou em conta tanto o vocabulário quanto a gramática. No vocabulário, optou-se por provérbios que apresentassem palavras potencialmente mais conhecidas pelos estudantes de inglês em nível básico, ajudando na motivação desses alunos, junto com palavras potencialmente menos conhecidas por eles, promovendo, assim, aprendizagem de vocabulário. Na gramática, cada provérbio deve ser exemplo de um ou mais elementos gramaticais dentro do limite da sequência gramatical previamente organizada. No entanto, considerando o número reduzido de provérbios, nem todos os tópicos gramaticais previstos para o primeiro ano do Ensino Médio foram contemplados, causando a redução da sequência gramatical. Esta limitação, porém, não impede que o material didático com provérbios cumpra o seu propósito de ajudar o discente no desenvolvimento da habilidade de leitura em inglês, pois pode ser utilizado como material suplementar, não dispensando outros materiais para o estudo do idioma. A estrutura do material, considerando a sequência dos provérbios e a sequência gramatical, com 
as correspondências entre cada provérbio e os tópicos gramaticais abordados, está demonstrada a seguir:

Tabela 1: Estrutura do material didático com a sequência dos provérbios e a sequência gramatical (tópicos gramaticais). Fonte: Própria

\begin{tabular}{|c|c|}
\hline SEQUÊNCIA DOS PROVÉRBIOS & $\begin{array}{c}\text { SEQUÊNCIA GRAMATICAL (TÓPICOS } \\
\text { GRAMATICAIS) }\end{array}$ \\
\hline \multirow[t]{3}{*}{ No man is an island. } & Adjetivo quantitativo \\
\hline & Verbo to be \\
\hline & Artigo indefinido: an \\
\hline \multirow[t]{2}{*}{ There's no time like the present. } & There is e there are \\
\hline & Artigo definido \\
\hline \multirow[t]{2}{*}{ Actions speak louder than words. } & Presente simples \\
\hline & Comparativo de superioridade de advérbios \\
\hline Practice makes perfect. & Presente simples ( $3^{\circ}$ pessoa do singular) \\
\hline \multirow[t]{2}{*}{ A man is as old as he feels. } & Artigo indefinido: $a$ \\
\hline & Comparativo de igualdade de adjetivos. \\
\hline Curiosity killed the cat. & Passado simples \\
\hline \multirow[t]{2}{*}{ Hope for the best, but prepare for the worst. } & Imperativo afirmativo \\
\hline & Conjunções \\
\hline \multirow[t]{2}{*}{ Don't bite the hand that feeds you. } & Imperativo negativo \\
\hline & Pronome relativo \\
\hline \multirow{2}{*}{$\begin{array}{l}\text { You can catch more flies with honey than } \\
\text { with vinegar }\end{array}$} & Verbo can (afirmativa) \\
\hline & Formação do plural dos substantivos \\
\hline \multirow[t]{2}{*}{ You can't judge a book by its cover. } & Verbo can (negativa) \\
\hline & Possessive adjectives \\
\hline
\end{tabular}

O material é composto de dez unidades didáticas. Cada um dos dez provérbios é objeto de estudo de cada unidade. A estrutura de cada unidade é composta de uma página de abertura, com o provérbio em destaque; uma página contendo uma questão sobre o conhecimento prévio do provérbio e uma atividade com palavras e expressões do provérbio para o estudante traduzir para o português, contemplando o trabalho com o vocabulário; de duas a quatro páginas com tópicos gramaticais constantes no provérbio; e uma página contendo uma questão sobre o significado do provérbio e exemplo de como o provérbio pode ser aplicado na prática, além de uma questão solicitando que o estudante compare a sua resposta da questão anterior, contida na 
mesma página, com a resposta dada por ele sobre o conhecimento prévio do provérbio.

A página de abertura da unidade didática mostra o provérbio em destaque, com letras maiores, coloridas e de fonte diferenciada. Acima do provérbio está escrito o número ordinal em inglês, correspondente à posição do provérbio no material e o nome proverb. (ex.: 1st proverb, 2 nd proverb etc.).

Na página seguinte foi elaborada a seguinte questão:

Quadro 1: Questão sobre conhecimento prévio do provérbio. Fonte: Material didático descrito nesta pesquisa.

Escreva o que consegue entender do provérbio, sem fazer nenhuma consulta nas páginas seguintes deste material e em outros materiais e recursos sobre o significado das palavras e expressões (obs.: não responda as questões seguintes sem antes responder esta questão e nem modifique a resposta desta questão depois de responder as questões seguintes).

A solicitação para não se fazer consulta tem o intuito de registrar o que o estudante sabe sobre o provérbio em inglês, sem tradução, acionando o conhecimento prévio. A resposta a esta questão é importante, pois servirá de comparação com o que ele aprendeu no final da unidade. A observação entre parênteses na questão enfatiza a importância de responder a questão antes de responder as seguintes, pois, do contrário, o aluno poderá responder influenciado pelas explicações e exercícios que se seguem, fugindo do propósito de ter uma resposta baseada no conhecimento prévio. Na mesma observação, solicita-se que não modifique a resposta da questão depois de responder as questões seguintes. Isso porque a resposta do estudante, mesmo que esteja parcialmente ou totalmente incorreta, ou em branco, é o registro do conhecimento prévio do aluno a ser comparado com o conhecimento adicional que ele irá adquirir sobre o provérbio depois de terminar a unidade didática. Todas as unidades apresentam esta questão.

$\mathrm{Na}$ sequência, na mesma página, há uma seção denominada “o vocabulário no provérbio", onde o estudante traduz palavras ou expressões do provérbio. Este exercício de tradução do vocabulário propõe que o discente responda primeiro as palavras e expressões que já sabe traduzir, possibilitando a verificação do que o aluno já sabe do vocabulário. Posteriormente, o estudante pesquisa os termos que não sabe traduzir, ampliando seu vocabulário.

As próximas páginas são dedicadas à exploração gramatical, com a seção “A gramática no provérbio". A abordagem gramatical no material didático para leitura em língua inglesa é aplicada ao provérbio e não pretende ser um fim em si mesmo. Assim, o estudante que deseja se aprofundar em um determinado tópico gramatical poderá consultar uma gramática e/o outro material para maiores detalhes. 
Os dezenove tópicos gramaticais do material didático, distribuídos nas dez unidades didáticas (vide tabela 1), estão numerados de 1 a 19. Abaixo do nome "tópico gramatical", com a sua numeração (ex.: tópico gramatical 1), é registrado o provérbio da unidade com uma palavra ou expressão sublinhada, indicando o assunto gramatical a ser abordado (ex. No man is an island:: a palavra sublinhada indica que o tópico gramatical aborda o artigo indefinido). Depois do provérbio tem a explicação gramatical e exercícios. Nem todos os tópicos gramaticais acompanham exercício.

A última página da unidade didática apresenta duas questões. A primeira é a que se segue:

Quadro 2: Questão sobre o significado do provérbio e seu exemplo prático. Fonte: Material didático descrito nesta pesquisa.

Depois de estudar os aspectos linguísticos (vocabulário e gramática), explique o significado do

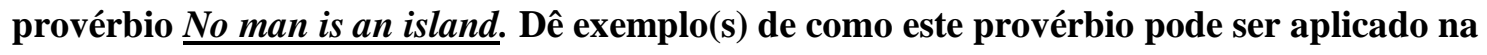
prática.

A noção de provérbio, explicitada na fundamentação teórica deste trabalho, com base em diversos autores já citados, inclui a finalidade desta unidade léxica fraseológica de aconselhar, ensinar, persuadir, enfatizar, advertir, consolar, repreender, incentivar etc. Lima (2011) sugere que essa finalidade do provérbio deve ser levada em consideração na abordagem dos provérbios no ensino de língua estrangeira. Ao solicitar a explicação do significado do provérbio da unidade didática e a exemplificação de como o provérbio pode ser aplicado na prática, a questão explicitada no quadro 2 permite que o estudante possa refletir sobre o provérbio, identificando a sua finalidade e a sua aplicação prática. Todas as unidades didáticas apresentam esta questão, com a alteração somente no provérbio de cada unidade.

A segunda questão da última página da unidade didática está assim proposta:

Quadro 3: Questão solicitando reflexão sobre o aprendizado do provérbio. Fonte: Material didático descrito nesta pesquisa

Compare sua resposta da questão anterior com a sua resposta sobre o que você consegue entender da frase na página [...]. As respostas estão parecidas, um pouco diferentes ou muito diferentes? Comente.

Ao responder à questão acima, o aluno tem a oportunidade de refletir sobre seu aprendizado. Se o estudante tiver respondido e tiver atendido as observações da questão exposta no quadro 1, poderá fazer uma reflexão mais precisa sobre a evolução da sua aprendizagem ao comparar a sua resposta da questão apresentada no quadro 1 com a sua resposta da questão 
exposta no quadro 2 .

A próxima fase da pesquisa foi a implementação (LEFFA, 2007), realizada com os discentes do $2^{\circ}$ ano do Curso Técnico Integrado em Edificações do IFPB, Campus Catolé do Rocha. Inicialmente o material foi aplicado com as duas turmas do $2^{\circ}$ ano com o início da primeira unidade didática. No entanto, considerando que as aulas de inglês ocorrem uma vez por semana, os alunos foram convidados para participarem da implementação do material didático nos horários que não coincidissem com as aulas regulares das disciplinas. Somente três alunos das duas turmas se voluntariaram para participar da atividade.

Durante a implementação, os estudantes receberam o material didático impresso e folhas em branco (folhas de respostas) para responder as questões solicitadas. Tanto o material didático quanto as folhas de respostas deveriam ser devolvidas pelos alunos para uma posterior observação. Os discentes foram convidados a ler o provérbio e a responder a primeira questão, atendendo todos os comandos nela expressos. Em caso de não souber a resposta da primeira questão, os estudantes escreveriam "não sei” ou similar.

A tradução das palavras e expressões constantes na seção "o vocabulário no provérbio" foi da seguinte forma: na folha de respostas, os alunos escreveram a expressão "sem consulta", depois, traduziram as palavras e expressões que já sabiam. As que não sabiam, os estudantes escreveram "não sei”. Depois, os alunos escreverem "com consulta” e depois registraram as respostas depois de consultarem um dicionário.

Em seguida, os estudantes receberam as folhas com os tópicos gramaticais. Foi lida e explicada cada tópico, organizada por itens para facilitar a leitura. Na sequência, os alunos fizeram os exercícios sobre o tópico gramatical, quando havia, seguida de correção em sala de aula.

Depois os discentes receberam a última folha da unidade didática, com as duas últimas questões (vide quadro 2 e 3). Após a resposta escrita, os estudantes foram convidados a falarem sua resposta em cada questão. Comparando as respostas para a questão ilustrada no quadro 1 com as respostas para a questão exposta no quadro 2, observou-se que a compreensão dos provérbios, em maior ou menor grau, foi ampliada. Os próprios alunos confirmam isso através de suas respostas a questão demonstrada no quadro 3.

A fase final da pesquisa consiste na avaliação do material didático. No final do último encontro da implementação do material, solicitou-se dos discentes que dessem sua opinião sobre o material didático. Eles relataram que o material é produtivo, ajudando a aprender várias palavras e expressões em inglês, que foi uma forma de ensino diferente da que estavam acostumados e que o material ajudou a refletir sobre o significado dos provérbios, aprendendo 
lições de vida expressas por estas frases. As respostas que os alunos escreveram nas folhas de resposta confirmam o relato positivo.

Quanto à revisão do material, verificou-se a necessidade de reelaborar algumas frases de um determinado exercício cujos verbos estavam conjugados na terceira pessoa do singular do presente simples, sendo este assunto gramatical abordado em tópico gramatical posterior. É oportuno observar que este exercício está relacionado a um outro assunto gramatical. Os outros trechos do material didático para revisão referem-se a equívocos ortográficos, como troca ou omissão de letras. É importante frisar que o material didático elaborado e descrito nesta pesquisa não é um produto definitivamente acabado, sendo passível de constantes revisões, mesmo depois de ser posteriormente disponibilizada.

\section{CONCLUSÕES}

O material didático de leitura em língua inglesa através de provérbios pretende ser uma opção para preencher uma lacuna existente entre o limitado conhecimento que muitos estudantes oriundos do Ensino Fundamental tem do idioma e a habilidade de leitura esperada destes alunos no Ensino Médio. Cabe aqui esclarecer que, embora o público alvo seja discentes do Ensino Médio, o material didático pode ser utilizado por qualquer pessoa que pretende desenvolver sua habilidade de leitura.

Foram seguidas as fases da produção de material didático propostas por Leffa (2007): análise, desenvolvimento, implementação e avaliação. Na análise, foi constatado, durante as aulas de Língua Inglesa, que muitos estudantes do IFPB Campus Catolé do Rocha apresentavam necessidade de desenvolver a habilidade de leitura. No desenvolvimento, o processo de elaboração material ocorreu desde o plano com sequências gramaticais até a concretização do material com as unidades didáticas completas. A implementação do material foi realizado com alunos do $2^{\circ}$ ano do Curso Técnico Integrado em Edificações do IFPB Campus Catolé do Rocha. A avaliação feita por estes alunos revelou-se positiva, com aprendizagem de palavras e expressões, além do significado e da reflexão que os provérbios proporcionaram, aprendendo lições de vida.

A produção de material didático de uma língua estrangeira é uma atividade que requer muito trabalho e conhecimento do idioma. Requer também planejamento, considerando a realidade dos estudantes. Esta pesquisa pretende contribuir para os estudos sobre produção de materiais didáticos de língua estrangeira, especialmente, de leitura em língua inglesa. Como um gênero textual de extensão curta, os provérbios tem demonstrado que são bastante eficazes para o aprendizado tanto de língua quanto de lições de vida. 


\section{REFERÊNCIAS}

50 more of the most important English proverbs. Phrase Mix. Disponível em: <http://www.phrasemix.com/collections/50-more-of-the-most-important-english-proverbs> Acesso em 08 out. 2018.

ALMEIDA, M. de F. O desafio de ler e escrever na escola: experiências com formação docente. João Pessoa: Ideia Editora, 2013.

AZEVEDO, P. P.; FERNANDES, L. C. A dupla função do provérbio: reiteração do mesmo e a imposição da subjetividade em gêneros discursivos do cotidiano. In: CELLI - COLÓQUIO DE ESTUDOS LINGUÍSTICOS E LITERÁRIOS. 3, 2007, Maringá. Anais... Maringá, 2009, p. 1965- 1973

DELL'ISOLA, R. L. P. Leitura: inferências e contexto sociocultural. Belo Horizonte: Formato, 2011.

DIAS, R.; JUCÁ, L.; FARIA, R. High up: ensino médio. Cotia: Macmillan, 2013. v. 1.

LEFFA, V. J. Como produzir materiais para o ensino de línguas. In: Produção de materiais de ensino: teoria e prática. 2. ed. rev. Pelotas: Educat, 2007. cap. 1.

LIMA, D. C. de. O uso de provérbios no ensino de língua estrangeira: uma análise contrastiva. In: Fólio - Revista de Letras. V. 3, n. 2, 2011, Vitória da Conquista. Ensaios, Vitória da Conquista, Universidade Estadual do Sudoeste da Bahia. jul./dez. 2011, p. 237-250.

MENEZES, V. et al. Alive high: inglês. São Paulo: Edições SM, 2013. v. 1.

SPEAKE, J. (Ed.). The Oxford Dictionary of Proverbs. $5^{\text {th }}$ Edition. New York: Oxford University Press, 2008

TAVARES, K.; FRANCO, C. Way to go !: língua estrangeira moderna - inglês. São Paulo: Ática, 2013. v. 1.

TILIO, R. (Org.). Voices plus. São Paulo : Richmond, 2016. v. 1.

VILAÇA, M. L. C. O material didático no ensino de língua estrangeira: definições, modalidades papéis. Revista Eletrônica do Instituto de Humanidades da Unigranrio. Vol. VII. N. XXX, jul.-set./2009.

XATARA, C. M.; SUCCI, T. M. Revisitando o conceito de provérbio. Juiz de Fora: Veredas, 2008. 